\title{
Resección de fibroma en mucosa oral. Técnica del
} estrangulamiento

\section{Resection of fibrous lesion in oral mucosa. Throttling technique}

\author{
Pablo Emilio Correa ${ }^{1 \otimes C \text { CuAC }}$, Sara Arias Mendieta ${ }^{2 \otimes}$
}

1. Cirujano Maxilofacial MBA profesor asistente Universidad CES. Medellín, Colombia.

2. Odontóloga Residente Cirugía Maxilofacial Universidad CES. Medellín, Colombia.

Fecha correspondencia:

Recibido: mayo de 2016.

Aceptado: junio de 2016.

Forma de citar:

Correa PE, Arias S.Resección de

fibroma en mucosa oral. Técnica

del estrangulamiento .Rev. CES

Odont 2016; 29(1): 82-87.

\section{Open Acces}

(C) Derecho de autor

Licencia creative commons

Ética de publicaciones

Revisión por pares

Gestión por Open Journal System

ISSN 0120-971X

e-ISSN 2215-9185

\section{Resumen}

El fibroma traumático es considerado un crecimiento tumoral benigno que aparece en cualquier órgano, pero lo hace con mayor frecuencia en la cavidad oral. Se define como, una hiperplasia reactiva de tejido conectivo fibroso, siendo su factor etiológico el traumatismo o la irritación local. Se presenta generalmente asintomático, en sitios como, mucosa de revestimiento, bordes laterales de lengua y reborde alveolar de pacientes edéntulos. La lesión por lo general no se asocia con síntomas y se observa con mayor frecuencia en adultos, pero puede encontrarse en individuos de cualquier sexo y edad. En el presente artículo, se proponen una técnica para la extirpación quirúrgica de la lesión. Es un procedimiento simple en el que se busca disminuir el aporte vascular. No requiere mayor tiempo operatorio, además no implica un riesgo importante, ni complicaciones intra o extraoperatorias para los pacientes. Las recurrencias no son frecuentes, a menos que no se elimine el factor irritante.

Palabras clave: Fibroma, etiología, técnicas de resección, tratamiento quirúrgico.

\section{Abstract}

The traumatic fibroma is considered a benign growth tumor that can appears in any organ, but it does most frequently in the oral cavity, and it is defined as a reactive hyperplasia of fibrous connective tissue, and it's etiological factor is trauma or local irritation. It usually occurs asymptomatic in places like mucosal lining, tongue and side edges of alveolar ridge of edentulous patients. The injury usually is not associated with symptoms and is most often seen in adults, but can be found in individuals of any age and gender. In the present article, a new technique is proposed, which consist of surgical removal of the lesion. It is a simple procedure in which decreased vascular supply pressure is proposed and does not require more operating time, also does not involve a significant risk or complications for patients. Recurrences are rare, unless the irritant factor is eliminated.

Keywords: Fibroma, etiology, resection techniques, surgical treatment. 


\section{Introducción}

El Fibroma es un crecimiento tumoral benigno derivado de tejido mesenquimal, que puede aparecer en cualquier órgano, siendo más frecuente en la cavidad oral, está asociado a traumatismo o irritación local. Puede presentarse en cualquier sitio de la cavidad oral, pero es visto con más frecuencia en mucosa de revestimiento, a lo largo del plano de oclusión, bordes laterales de lengua, labio inferior, reborde alveolar edéntulo. El diámetro puede variar de $1 \mathrm{~mm}$ a $2 \mathrm{~cm}$ aproximadamente $(1,4)$.

Aparece como un nódulo de color rosa, de superficie lisa, similar a la mucosa que lo rodea, de base sésil o pedunculada y consistencia dura. En algunos casos la superficie puede aparecer blanca, como resultado de la hiperqueratosis, causada por la irritación continua o ulcerada por traumatismos repetidos (cálculos, márgenes sobresalientes, restauraciones, cuerpos extraños) (1- $\underline{3})$.

Histológicamente se presenta como una masa nodular sólida, no encapsulada, cubierta por epitelio escamoso estratificado, tejido conectivo denso con presencia de colágeno tipo I y III, dispuesto al azar y en ocasiones tejido conectivo fibroso hialinizado. Puede haber infiltrado inflamatorio crónico que contiene en su mayoría linfocitos y células plasmáticas, también pequeños vasos sanguíneos, factores de crecimiento producidos por el epitelio, que atraviesan la membrana basal y se unen a algún receptor en el fibroblasto, que da inicio a la producción de colágeno, formando un tejido cicatrizal más pálido y firme que la mucosa $(1,2,4)$. Sin embargo, es dudoso que represente una verdadera neoplasia en la mayoría de las instancias. Se define más bien, como una hiperplasia reactiva de tejido conectivo fibroso en respuesta a una irritación local o traumatismo $(1,4)$.

La lesión por lo general no produce síntomas, excepto cuando presenta una superficie ulcerada, con presencia de dolor e inflamación. Es más común en la cuarta y sexta décadas, con una relación hombre - mujer 1:2. (1,4).

Se conoce también como fibroma irritacional, fibroma traumático, hiperplasia fibrosa focal, nódulo fibroso, pólipo fibroepitelial. El fibroma es considerado benigno. $(1, \underline{3})$ se observa con más frecuencia en adultos, pero puede ocurrir en individuos de cualquier edad y sexo.

\section{Tratamiento Convencional}

El fibroma es removido mediante una escisión quirúrgica, sin necesidad de remover tejido mucoso adyacente. Las recurrencias no son frecuentes, a menos que no se elimine el factor irritante. Es importante analizar el tejido mediante un examen microscópico, porque otros tumores benignos y malignos, simulan la apariencia del fibroma (4).

Se debe realizar una anamnesis cuidadosa y el examen clínico para evidenciar la naturaleza y la causa-efecto de la lesión. Cuando existe un origen traumático y una respuesta queratósica, se recomienda un periodo de observación de dos semanas previa eliminación del factor causal, no se requiere biopsia. Cuando la lesión ha mostrado crecimiento rápido o se duda de la etiología, se recomienda realizar estudio histopatológico para establecer el diagnóstico definitivo.

Se aplica anestesia perilesionar para la analgesia y vasoconstricción del tejido, posteriormente se procede a la eliminación quirúrgica con bisturí $n^{\circ} 15$ y un corte en 
Enero - Junio 2016 - Pág 84

tajada de naranja que incluya toda la lesión para evitar recidiva e incluyendo además eliminación de factor irritante, finalmente se sutura con seda tres ceros. Se formula Amoxicilina 500 mg por 7 días cada 8 horas, Ibuprofeno 400 mg durante 3 días cada 8 horas y se cita en 8 días para revisión y retiro de sutura. Regularmente no se encuentra presencia de complicación postoperatoria, observándose un tejido sano con igual color a la mucosa bucal $(\underline{1}, \underline{5}-\underline{7})$.

Existen otras alternativas de tratamiento para este tipo de lesiones como la criocirugía, que utiliza nitrógeno líquido, lo que resulta muy útil en casos de pacientes con alto riesgo para cirugía o alérgicos a la anestesia. Tiene como limitación el no poder realizar el respectivo estudio histopatológico de las muestras de pequeño tamaño (7).

Otras técnicas utilizadas son, el bisturí frío, el bisturí eléctrico, laser de Erbio, laser de neodimio y laser de diodo. Otros autores proponen infiltrar la lesión con Penicilina G, afirmando que esta produce esclerosis de la lesión, desprendiéndola y evitando la recidiva (ㅇ) .

El uso del láser de dióxido de carbono se ha convertido en un modo de terapia para las lesiones gingivales, debido a las características únicas de la herida y la facilidad de uso (6).

\section{Técnica de estrangulamiento}

Se propone la siguiente técnica para resección de fibromas de $5 \mathrm{~mm}$ o menos en mucosa oral de labios (Figura 1a), carrillos y dorso lingual (Figura 2a).

\section{Fibroma en Carrillo}

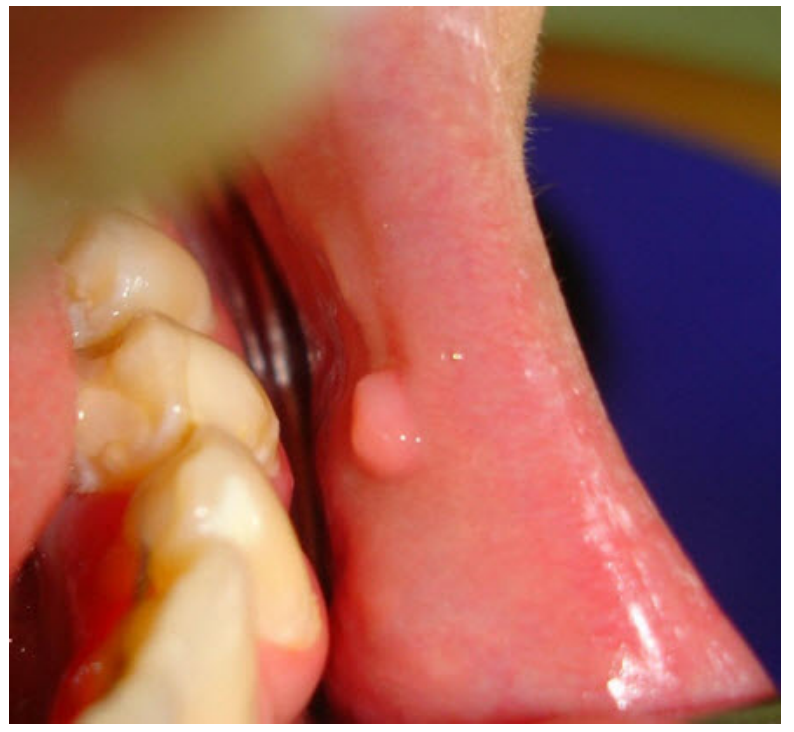

Q Figura 1a. Aspecto clínico de la lesión.

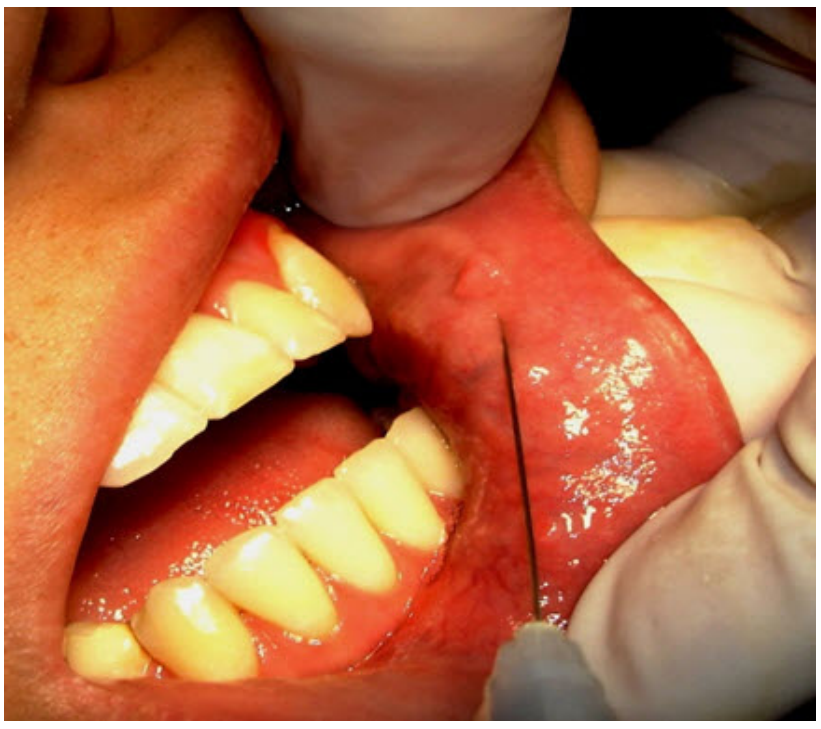

Figura 1b. Aplicación de anestesia perilesionar

Luego de realizar infiltración con anestésico local (Figura 1b), se utiliza seda dental para rodear la lesión (Figura 1c, 2b) y se anuda de manera firme tratando de ejercer presión de tal manera que se disminuya al máximo el aporte vascular de la lesión, la cual empieza a tener una coloración pálida (Figura 1d, 2c). Luego se rodea de nuevo la lesión en dos o tres ocasiones más, haciendo nudo en cada vuelta. Se espera 3 minutos aproximadamente y se procede a traccionar un poco la lesión con la seda dental descubriendo la base (Figura 1e). Con hoja de bisturí $N^{\circ} 15$ se incide la base de la lesión retirándola del tejido adyacente, quedando unida a la seda dental (Figura 1f). El lecho del tejido aparece levemente retraído, sin sangrado (Figura 1g, 2d); de esta manera termina el procedimiento. No es necesario realizar sutura (Figura 2e). 


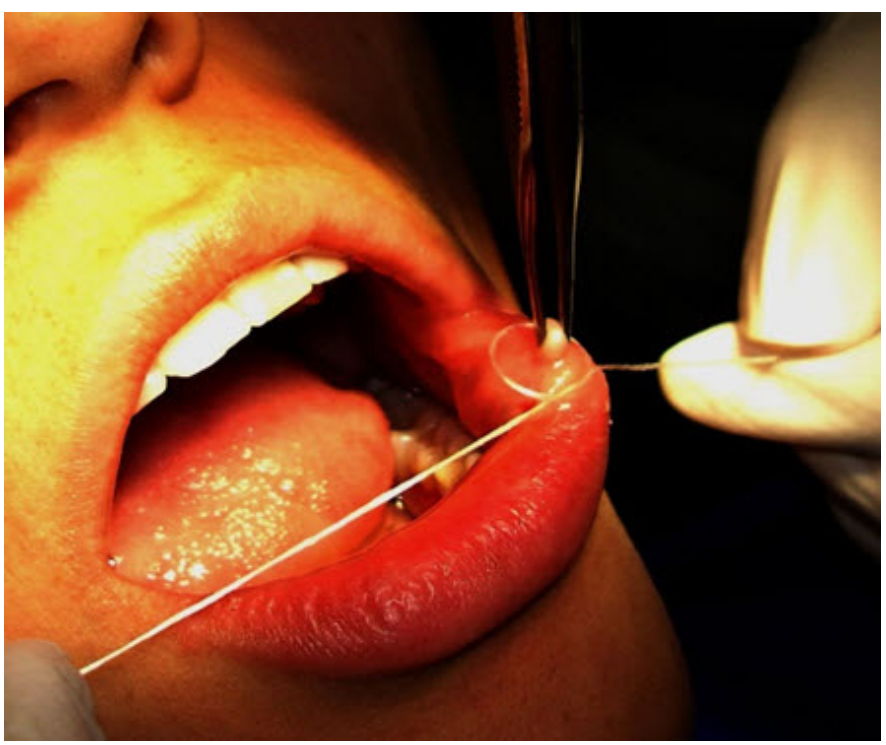

Q

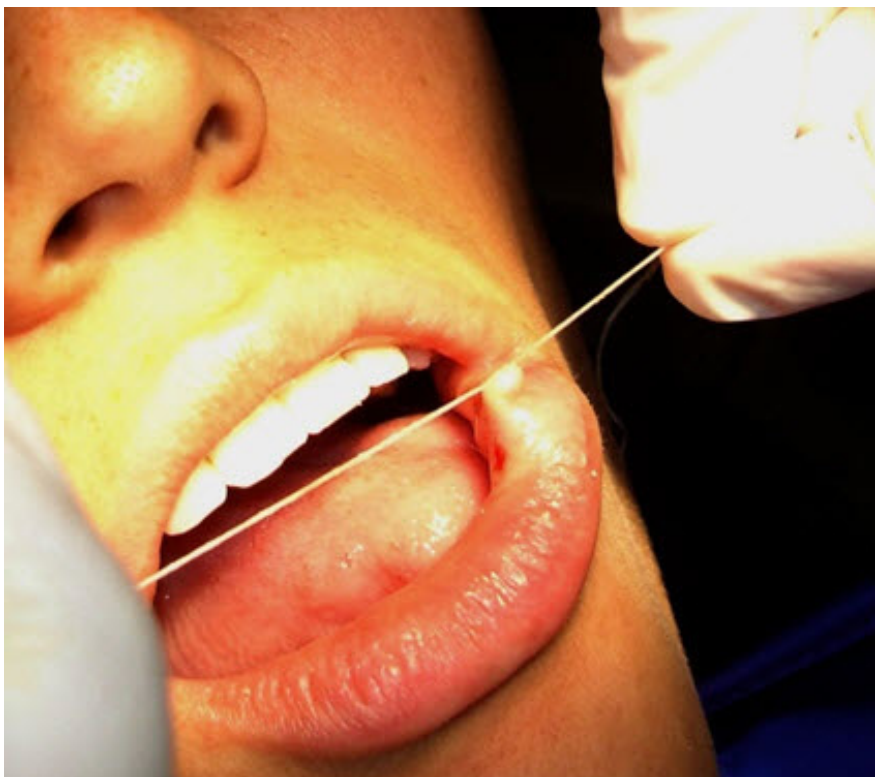

Q Figura 1e. Se procede a traccionar la lesión.

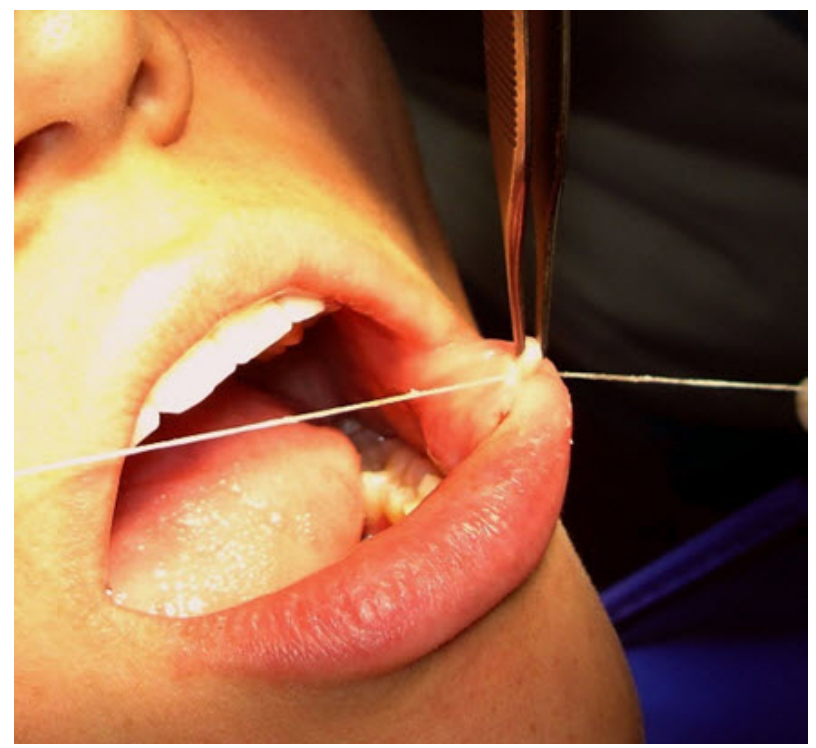

Figura 1d. Se realiza presión para disminuir el aporte vascular $\mathbf{Q}$

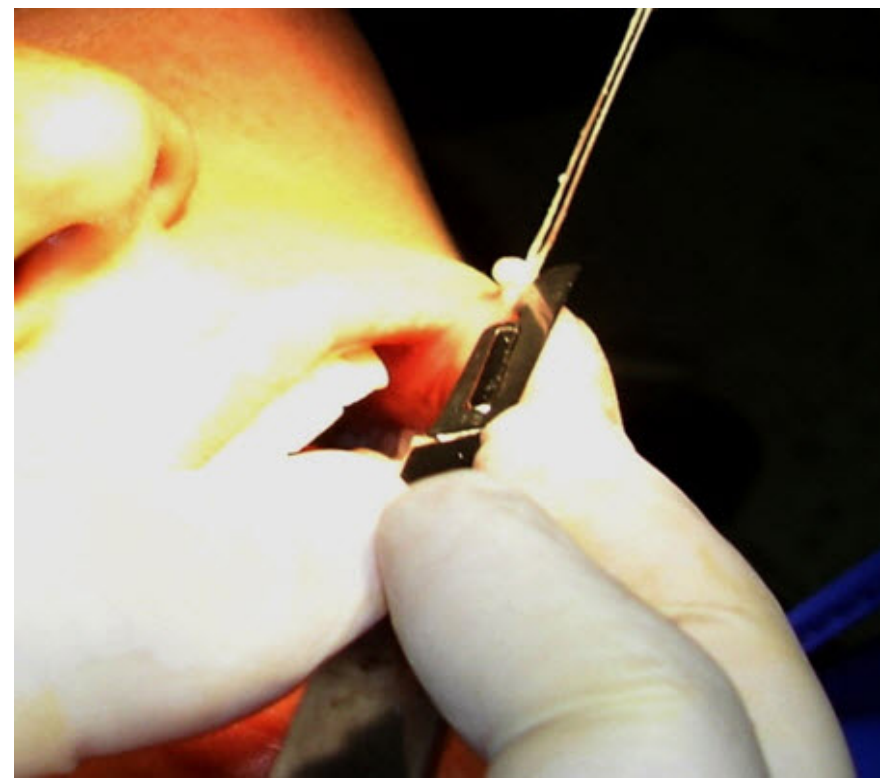

Figura 1f. Incisión de la base de la lesión

Q

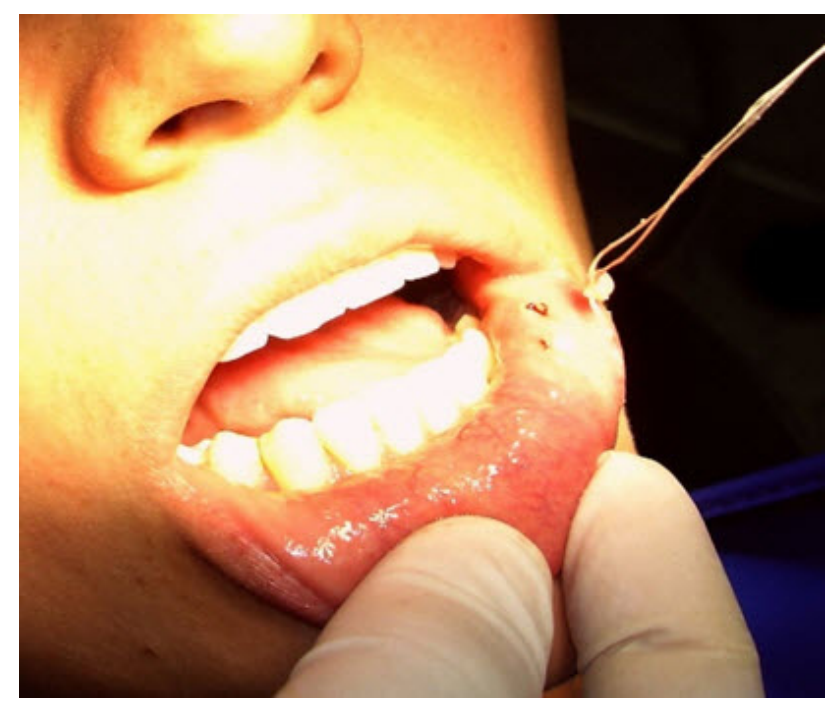

Q Figura 1g. Remoción de la lesión del tejido adyacente. 
Enero - Junio 2016 - Pág 86

\section{Fibroma en Borde Lateral de Lengua}

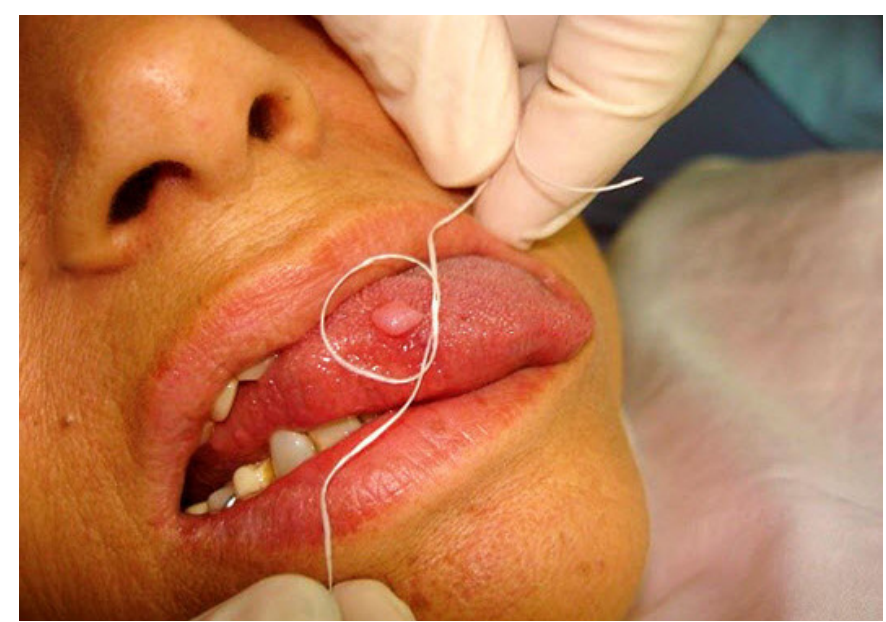

Q Figura 2a. Localización y aspecto clínico de la lesión.

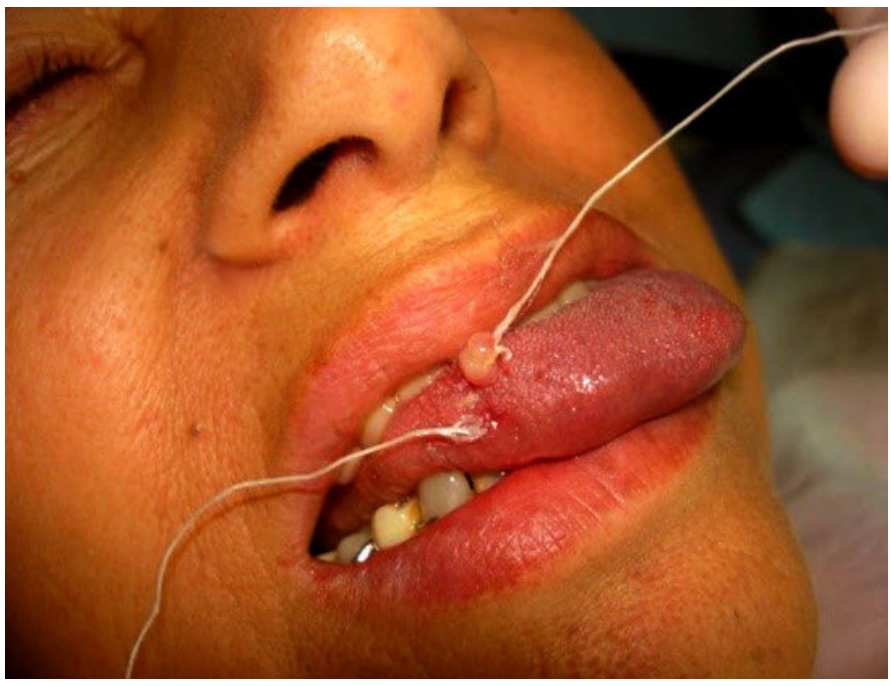

Q

Figura 2c. Se presiona el tejido para disminuir el aporte vascular.

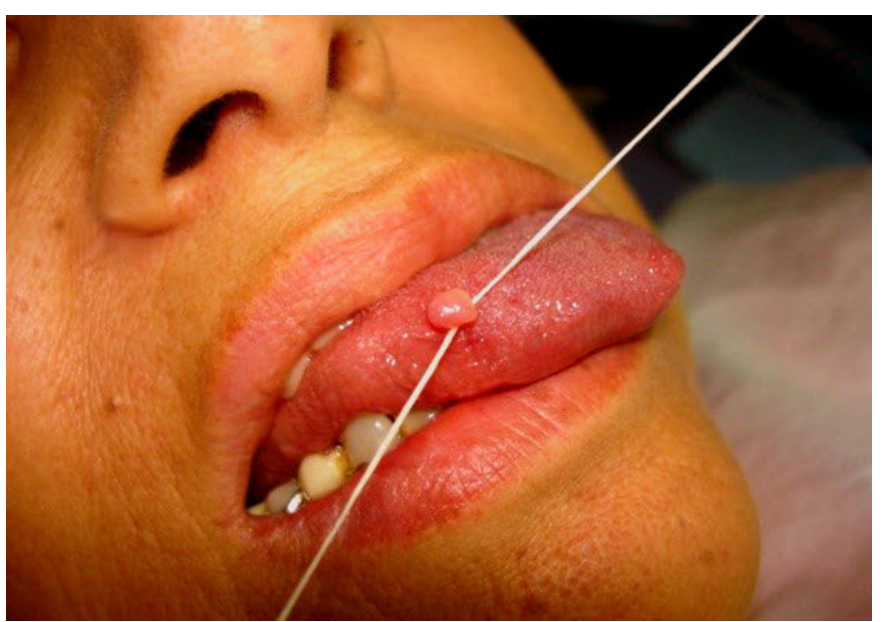

Figura 2b. Técnica de anudado.

Q

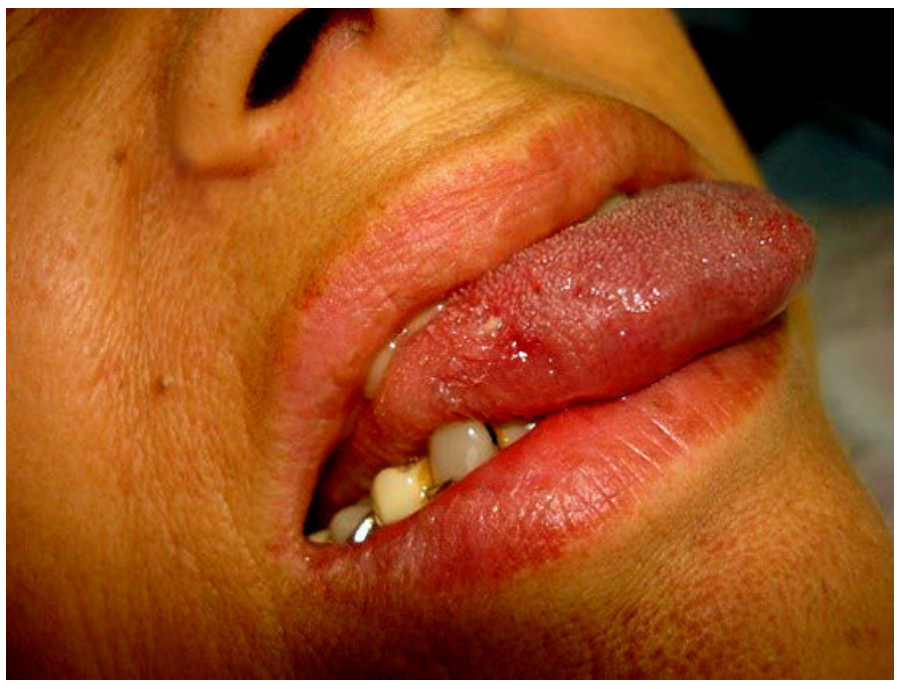

Q

Figura 2d. Aspecto clínico del tejido luego de realizado el procedimiento.

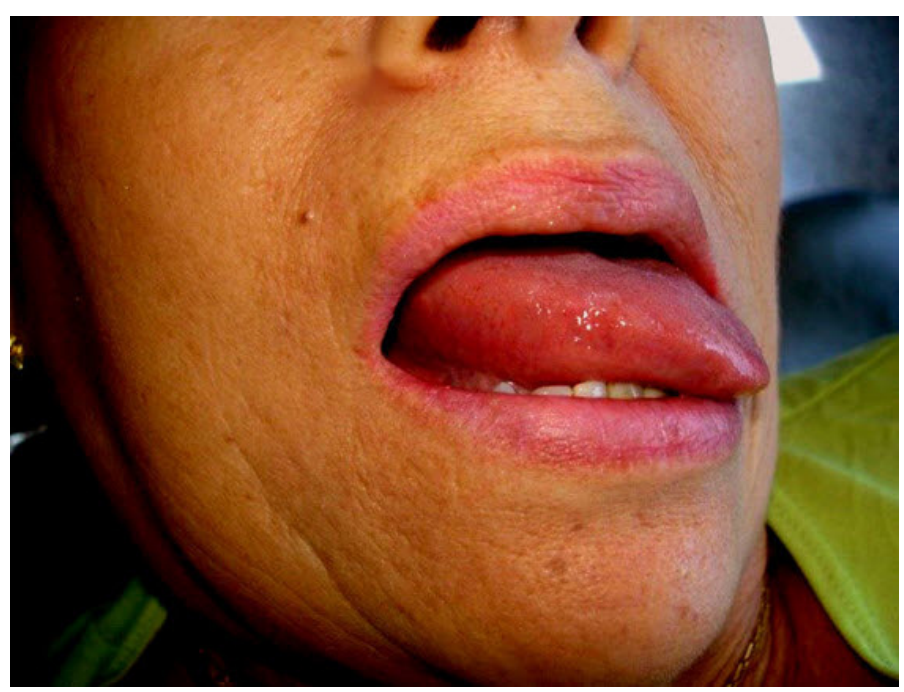

Figura 2e. Tejido cicatrizado. 


\section{Discusión}

Se considera el fibroma traumático como una neoplasia benigna de tejido mesenquimal, que aparece con mayor frecuencia en la cavidad oral, su diámetro puede variar de $1 \mathrm{~mm}$ a $2 \mathrm{~cm}$ aproximadamente, la lesión es causada por trauma o irritación local. Los picos de prevalencia se presentan en la cuarta y sexta décadas de la vida, con predominio por el género femenino.

Tiene apariencia de nódulo de color rosa, superficie lisa, similar a la mucosa, base sésil o pedunculada y consistencia dura. La lesión por lo general no está acompañada de síntomas, a menos que su superficie se encuentre ulcerada.

Se encuentra que, la técnica descrita difiere de la resección quirúrgica convencional, al no considerar necesaria la remoción de tejido sano adyacente para evitar la recidiva de la lesión, no se realiza presión de la lesión para disminuir el aporte vascular, no se sutura, ni se formula medicamento antibiótico y no se utiliza técnicas adicionales como las mencionadas anteriormente, bisturí frío o eléctrico, laser de Erbio, entre otras.

\section{Conclusiones}

La técnica de estrangulamiento, es un procedimiento sencillo, rápido, no produce sangrado, no es necesario suturar, por lo tanto tampoco se requiere del retiro de sutura en la cita de revisión, no implica un riesgo de complicaciones importantes tanto intra como extraoperatorias. Debe eliminarse el factor irritante para evitar recidiva y realizar seguimiento clínico durante dos semanas cuando existió un origen traumático y respuesta queratósica.

\section{Bibliografía}

1. Daddy Suradi Halim, Abdullah Pohchi, Pang EE Yi. The Prevalence of Fibroma in Oral Mucosa Among Patient Attending USM Dental Clinic Year 2006-2010. The Indonesian J Dent Res.2010;1(1):61-66. link

2. Anjali Singh, Manoj Vengal, Neelkant Patil, Suresh K. Sachdeva. Traumatic fibroma - A saga of reaction against irritation. Dental Impact.2012;4(1):49-52.

3. Mohammed Nazish Alam, S.C Chandrasekaran, Mohan Valiathan. Fibroma of the ginigiva: A case report of 20 years old lesion. IJCD.2010;1(3):107-109. link

4. Moret Yuly, López-Labady Jeaneth, Cuberos Mara, Camacho Anadina, González José María. Fibroma traumático: Dos presentaciones clínicas una misma entidad. Acta Odontológica Venezolana. 2012; 50 (4). Link

5. Suárez D, Vanegas S, Santos M, Godoy A. Fibroma traumático evaluación clínica e histológica de un caso. Acta Bioclínica. 2011; 1(1). link

6. Rossmann JA. Reactive Lesions of the Gingiva: Diagnosis and Treatment Options. The Open Pathology Journal.2011; 5: 23-32.

7. López-Labady J, Villarroel M, Lazarde J, Rivera H. Fibroma Traumático. Revisión de la literatura y reporte de dos casos. Acta Odontológica Venezolana. 2000; 38(1):47-49. link

8. Borras MT, Delgado-Molina E, Berini-Aytés L, Gay-Escoda C. Exeresis de las lesiones hiperplásicas de la cavidad bucal. Estudio retrospectivo de 128 casos. Med. Oral Patol. Oral Cir. Bucal. 2005; 10(2):151-162. 


\section{Maestría en Ciencias Odontológicas \\ Registro calificado 3585 del 29 de abril de 2011 - Código SNIES 91294}

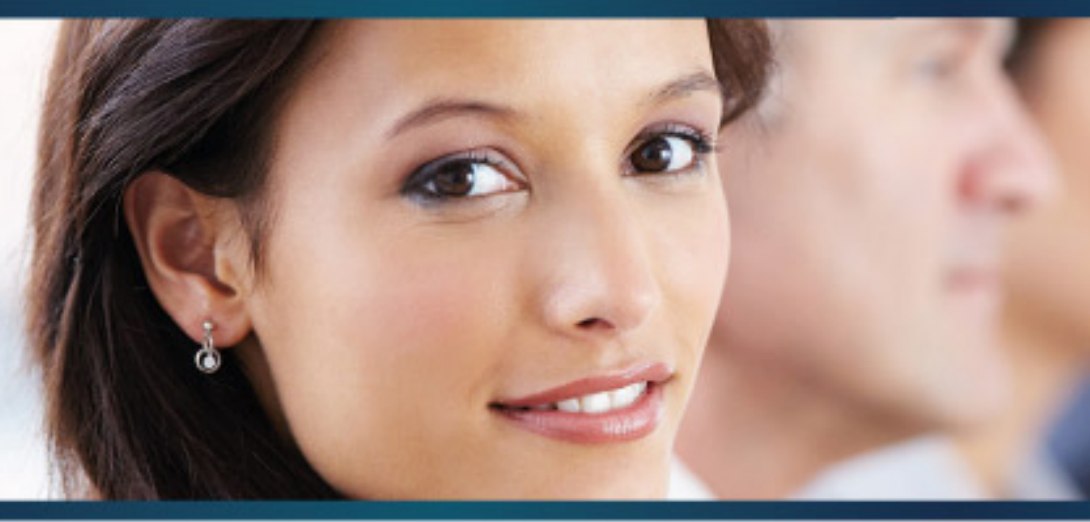

\section{Duración: 4 semestres | Modalidad: Presencial - Tiempo parcial}

La Maestría en Ciencias Odontológicas que ofrece la Facultad de Odontología de la Universidad CES de Medellín, ha sido pensada para brindarle a la profesión, la oportunidad de fundamentar el conocimiento científico y tecnológico, en la odontología basada en la evidencia, la aplicación de las ciencias básicas y la odontología contemporánea, de manera que su ejercicio clínico, investigativo y académico sean parte del proyecto de vida del profesional y acorde con el contexto global.

Proporciona al profesional un perfil ocupacional más competitivo con una visión más amplia dentro de un ámbito investigativo, fundamentado siempre en procurar la mejor evidencia, para la toma de decisiones profesionales acertadas en cualquier nivel de desempeño de la misma.

\section{Objetivo general}

Formación de profesionales e investigadores de alto perfil académico, capaces de liderar proyectos y equipos de investigación orientados hacia la generación de nuevo conocimiento en el ámbito de la salud y en especial en la cavidad bucal.

\section{La Maestria cuenta con tres grandes áreas de formación:}

- Investigación Científica - Epidemiología y Bioestadística

- Ciencias Básicas y Clínicas aplicadas a la investigación en odontología

Áreas soportadas e implementadas a través de los tres grupos de investigación de la Facultad de Odontología:

- Grupo de Labio y Paladar Hendido, Fisiología Oral y Crecimiento Craneofacial -CES-LPH

- Grupo de Investigación en Bioingeniería -GIB

- Grupo de Investigación Básica y Clínica en Odontología -CBO.

Los cuales se encuentran clasificados en Colciencias. A través de ellos se desarrollan doce líneas de investigación que abarcan todas las áreas clínicas de la odontología.

Informes: E-mails: asaldarriaga@ces.edu.co ddurango@ces.edu.co - pcorrea@ces.edu.co Teléfono: 4440555 ext: 1550 - 1231

Proceso de inscripción y requisitos ingresar a la página web:

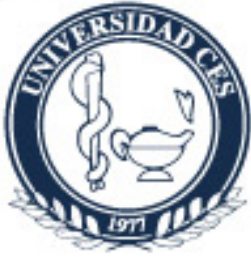

UNIVERSIDADCES

Un compromiso con la excelencia

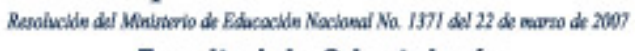

Facultad de Odontología 